This is a long and excellent book and well worth the price.

$$
\begin{gathered}
\text { F. R. VICARY } \\
\text { Department of Medicine, } \\
\text { Royal Northern Hospital, } \\
\text { London }
\end{gathered}
$$

\section{Dictionary of Medical Ethics}

Edited by A. S. Duncan, G. R. Dunstan and R. B. Welbourn. Revised and enlarged. Pp. xxxi +459, Darton, Longman and Todd, London, 1981. £12.50.

The status of the medical profession rests not only on the service provided, it reflects society's trust in the standards of practice observed. At all levels this implies that moral obligations govern the conduct of doctors, and indeed the possession of a corporate ethics could be regarded as one of the essential marks of a profession. The publication within 4 years of a second revised and enlarged edition of this Dictionary confirms the current interest in this controversial field. There is now an introduction containing erudite essays on the evolution of Medical Science and of Medical Ethics. They are written by the editors and link the concepts underlying the book to the succeeding reference format. Subjects are taken from $A$ to $W$ with 148 authors contributing. In some entries, such as 'Abortion', an additional editorial comment is provided. The book is intended for the layman as well as the doctor, thus many subjects such as 'General Practice' or 'Intensive Care Units' give basic facts on the speciality, followed by a discussion of the related moral issues. The principal ethical theories and traditions are explained and the main International Declarations on medical practice, experimentation, and the determination of death are recorded in detail. There is extensive cross-referencing, and useful bibliographies are provided on many topics. As a mine of immediate information and a detailed reference guide to further study this work is unrivalled. Since medical ethics reflect important issues which involve society as a whole, authoritative, dispassionate and clear information must be made widely available. This book will undoubtedly go far to promote this end and will usefully stimulate and inform discussion.

\section{J. BRUeton Westminster Children's Hospital,} London

\section{Emergency Psychiatry for the House Officer}

By W. R. Dubin and R. Stolberg. Pp. 166. MTP Press, Lancaster, 1981. £8.95.

Whether he sees himself as having psychiatric skills or not, the House Officer in the A \& E Department is going to be faced with the management of psychiatric emergencies. Violence, drug abuse, alcoholism, psychoses, suicide attempts, confusional states and plain human distress and fear will confront him frequently. He (or she, of course) may feel inadequate, frightened, impatient or irritated by such patients, but ignoring the problem won't make it go away.

This practical manual by two American psychiatrists written expressly for the non-psychiatric house officer should go some way towards increasing confidence in dealing with psychiatric emergencies. They give many excellent practical hints from how to approach the distressed patient ('How can we help you Mr Smith' rather than the patronising 'What's the matter Joe') to techniques for coping with those brandishing fire arms. Fortunately, the latter seem to be commoner in the U.S.A. where 'security guards' (sic) are more readily available than in the average British $A$ \& $E$ Department.
The psychiatric presentation of organic disorders is well covered, even though perhaps inappropriately elaborate investigations for the emergency department (such as EEG and $B_{12}$ levels) are listed-but this is no doubt for the sake of completeness. There are useful tips on eliciting and interpreting a psychiatric history.

This relatively short but expensive paperback volume may be marred for some by the rather too comprehensive lists of symptoms, differential diagnoses and investigations, but overall it should prove a useful book for the duty room of a casualty department.

As the book is American, the U.S.A. trade names for drugs are bracketed with the official names which may cause some confusion. There is an appendix of some 58 pages (out of a total 166) listing virtually every drug in the pharmacopoeia and the names of commercial preparations. This long list purports to show which drugs have possible psychiatric side effects, though as many have none, or are non-specific, it would seem unnecessary to inflate this book by a third. Again, because of its American origin, no mention is made of the working of the Mental Health Act which would be useful for inclusion in such a manual for use in this country.

J. J. BRADLEY

Psychiatric Wing,

Whittington Hospital, London

\section{Microbiology for Clinicians}

By R. N. Grüneberg. Pp. 179, illustrated. MTP Press, Lancaster. University Park Press, Baltimore, 1981. f11.95.

This little book dedicated to Joan Stokes maintains the purposeful clinical tradition which she herself originated in her work and writings.

It is not, nor does it affect to be, a text book. Early chapters discuss the pathogenicity and the differences between colonization and infection. There follows a chapter on the bacteriology laboratory including succinct descriptions of the various bacteria, their classification and the mechanisms by which they cause disease in man. Viruses, fungi and parasites have a single chapter in which the clinical significance of isolation and serological investigations are discussed. Probably the best chapter is on the anti-bacterial drugs in which Grüneberg's particular interest is reflected. His opinions on antibiotic combinations, the use of bactericidal drugs and the discussion on prophylactic chemotherapy are well informed and balanced in their treatment.

Infections in general practice are discussed in a separate chapter with advice on how best the microbiology laboratory might be used in these cases and there are separate chapters on infections commonly met with in hospitals, the use of the laboratory in outbreaks of infection, and the control of infection in the community; the last includes a discussion on public health, the containment of infection, immunization, and health education.

The microbiological missionary zeal of Grüneberg becomes readily apparent in the didactic and perhaps even inflexible chapters on the control of infection in hospitals and the control of antibiotic resistance; these rewarding chapters lay down very practical guidelines and describe clearly effective measures for the control of both. These are areas of unavoidable clinical involvement of microbiologists who will be very familiar with the problems described and will benefit from some of the solutions advised.

There is a final chapter which has an exciting and optimistic look into the future; that a note of pessimism creeps into this chapter is really due to Dr Grüneberg's unhappiness with the current control of antibiotic use and his fears that ill-judged and profligate use of valuable antibacterials will lead to less and less successful therapy in the future. 